\section{Extensão, assessoria técnica e moradia popular: Vila Nazaré e a ocupação Povo Sem Medo de Porto Alegre (Brasil)}

\author{
Bruno Cesar Euphrasio de Mello \\ brunocesaremello@ufrgs.br \\ (iD) orcid.org/0000-0003-1694-157X \\ Inês Martina Lersch \\ martina.lersch@ufrgs.br \\ (iD) orcid.org/0000-0002-5672-4644 \\ Bárbara Bundyra Finger \\ fingerba@gmail.com \\ (iD) orcid.org/0000-0003-4954-7210
}

RECEPCIÓN: 21/04/20

ACEPTACIÓN FINAL: 13/05/20

\section{Resumo}

$\mathrm{O}$ artigo relata as atividades realizadas pelo projeto de extensão Práticas Urbanas Emergentes (2019) em dois territórios na cidade de Porto Alegre - RS: a Vila Nazaré e a Ocupação Povo Sem Medo de Porto Alegre. Em sua segunda edição, o projeto de extensão pautou suas ações na assessoria técnica em Arquitetura e Urbanismo e no debate sobre direito à cidade e à moradia digna. A Vila e a Ocupação devem ser compreendidas no contexto da ampliação da pista de pousos e decolagens do aeroporto internacional Salgado Filho e a consequente remoção das famílias de seu território. As ações realizadas e os debates que emergiram do projeto de extensão tomaram dois pressupostos como referência: a proposta de educação crítica, participativa e solidária (Betto, 2018); e as concepções de dialogicidade e práxis (Freire, 1987).

Palavras-chave: Extensão universitária; ocupações; assessoria técnica; habitação popular; urbanismo; Brasil

\author{
Hemilyn da Silva Machado \\ hemilyndasilva@hotmail.com \\ (iD) orcid.org/0000-0002-3765-0010 \\ Universidade Federal do Rio Grande \\ do Sul, Brasil
}

Extension, technical advisory and popular housing: Pueblo Nazaré and the occupation Fearless People of Porto Alegre (Brazil)

\section{Abstract}

The article reports on the activiti escarried out by the Emerging Urban Practices (2019) extension project in two territories in Porto Alegre - RS: Vila Nazaré and occupation Povo Sem Medo de Porto Alegre. In its second edition, the extension project guided its actions in the technical consultancy in Architecture and Urban Planning and in the debate on the right to the city and decent housing. The Village and the occupation must be understood in the contexto of the expansion of the runway of the landings and take off of the International Airport Salgado Filho and the consequente removal of families from their territory. The actions carried out and the debates that emerged from the extension project took two assumptions as a reference: the proposal for critical, participatory and solidary education (Betto, 2018) and the concepts of dialogicity and praxis (Freire, 1987).

Keywords: University extension; occupations; technical assistance; popular housing; urban planning; Brazil
Sujetos y relaciones en extensión universitaria / Intervenciones 다(1)(2)
Extensión, asesoramiento técnico y vivienda popular: Vila Nazaré y la ocupación del Pueblo Sin Miedo de Porto Alegre (Brasil)

\section{Resumen}

El artículo informa sobre las actividades realizadas por el proyecto de extensión de Prácticas Urbanas Emergentes (2019) en dos territorios de la ciudad de Porto Alegre - RS: el Pueblo Nazaré y la ocupación Pueblo Sin Miedo de Porto Alegre. En su segunda edición, el proyecto de extensión guió sus acciones en la consultoría técnica en Arquitectura y Urbanismo y en el debate sobre el derecho a la ciudad y a la vivienda digna. El pueblo y la ocupación deben entenderse en el contexto de la expansión de la pista de aterrizajes y despegues en el Aeropuerto Internacional Salgado Filho y el consiguiente traslado de familias de su territorio. Las acciones llevadas a cabo y los debates que surgieron del proyecto de extensión tomaron como referencia dos supuestos: la propuesta de educación crítica, participativa y solidaria (Betto, 2018) y los conceptos de dialogicidad y praxis (Freire, 1987).

Palabras clave: Extensión universitaria; ocupaciones; asesoramiento técnico; vivienda popular; urbanismo; Brasil

Para citación de este artículo: De Mello, B. C. E.; Bundyra Finger, B. y Da Silva Machado, H. (2020) Extensão, assessoria técnica e moradia popular: Vila Nazaré e a ocupação Povo Sem Medo de Porto Alegre (Brasil). +E: Revista de Extensión Universitaria, 10(12), 1-12. doi: 10.14409/ extension.v10i12.Ene-Jun.9059. 


\section{Introdução}

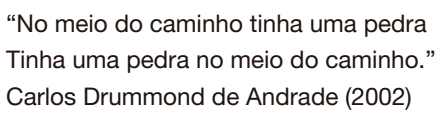

O atual governo federal brasileiro elegeu a Universidade Pública e os movimentos sociais como seus principais adversários. De um lado, o chefe do Poder Executivo e seus ministros desqualificam publicamente o ambiente acadêmico, descrevendo-o como espaço da "balbúrdia" e improdutividade e cortando investimentos do ensino público; de outro, criminalizam os movimentos sociais que lutam, por exemplo, pelo direito à moradia e à cidade.

Neste contexto, o Projeto de Extensão "Práticas Urbanas Emergentes (PUE) - Ano II" (2019), da Faculdade de Arquitetura da Universidade Federal do Rio Grande do Sul (UFRGS), promoveu a interlocução entre comunidade acadêmica (professores, estudantes de graduação e pós-graduação, além de egressos) e atores sociais (líderes comunitários e de movimentos sociais organizados, moradores de ocupações e bairros populares) com propósito de: i) vincular a Universidade ao meio onde ela está inserida; ii) discutir a reivindicação por direito à moradia e à cidade a partir da perspectiva dos movimentos sociais; iii) colaborar com demandas sociais concretas por meio do exercício da Assessoria Técnica em Arquitetura e Urbanismo.

O método adotado foi organizado em dois momentos: a realização de vivências e oficinas. As vivências foram saídas a campo, onde a comunidade acadêmica e atores sociais interagiram no território próprio das práticas urbanas emergentes. As oficinas, por sua vez, foram momentos de troca de ideias e de experiências que ocorreram na Universidade. Este movimento de ida e vinda (território-universidade) deu-se pela necessidade de associar ação e reflexão, além de ter como premissa o diálogo entre os diversos saberes sobre a cidade.

Nesta edição, o PUE realizou atividades junto a dois sítios distintos, mas muito próximos fisicamente: a Vila Nazaré e a Ocupação Povo Sem Medo de Porto Alegre (PSM/POA), esta última organizada pelo Movimento dos Trabalhadores Sem Teto (MTST). O conflito posto no território onde estão situadas a Vila e a Ocupação é complexo e envolve muitos atores e facetas.

A proposta inicial da Ocupação PSM/POA, constituída em setembro de 2017, era denunciar a disputa territorial entre a Fraport Brasil/Porto Alegre, subsidiária da Fraport AG Frankfurt Airport Services Worldwide (empresa alemã que venceu a concessão para operar - Aeroporto Salgado Filho) e a Vila Nazaré, comunidade pobre que abriga aproximadamente 1.500 famílias e que está sendo arrasada, visando à ampliação da pista do aeroporto.

A Vila e a Ocupação se localizam na Zona Norte da capital gaúcha, junto à Várzea do Rio Gravataí (Figura 1), área ambientalmente frágil, cuja fauna e flora já foram degradadas pela poluição das águas e pelo acúmulo de lixo. Paradoxalmente, nesse mesmo local estão sendo realizadas obras de infraestrutura para oferecer melhores condições à implantação de condomínios empresariais e galpões de apoio à atividade aeroportuária, o que já resultou no aumento do preço da terra - inviabilizando ali a moradia popular.

A fim de melhor situar a relação entre tal contexto e a atividade extensionista, é importante esclarecer que o Projeto de Extensão PUE se apoiou na Lei 11.888/08, a qual assegura às famílias de baixa renda assistência técnica pública e gratuita para o projeto e a construção 
de habitação de interesse social (ATHIS). Adotá-la como parâmetro de atuação possibilitou discutir seus potenciais e limitações a partir de seu efetivo exercício.

\section{Figura 1: Localização da Vila Nazaré, da ocupação Povo Sem Medo e do Aeroporto Salgado Filho,} todos situados na Várzea do Rio Gravataí

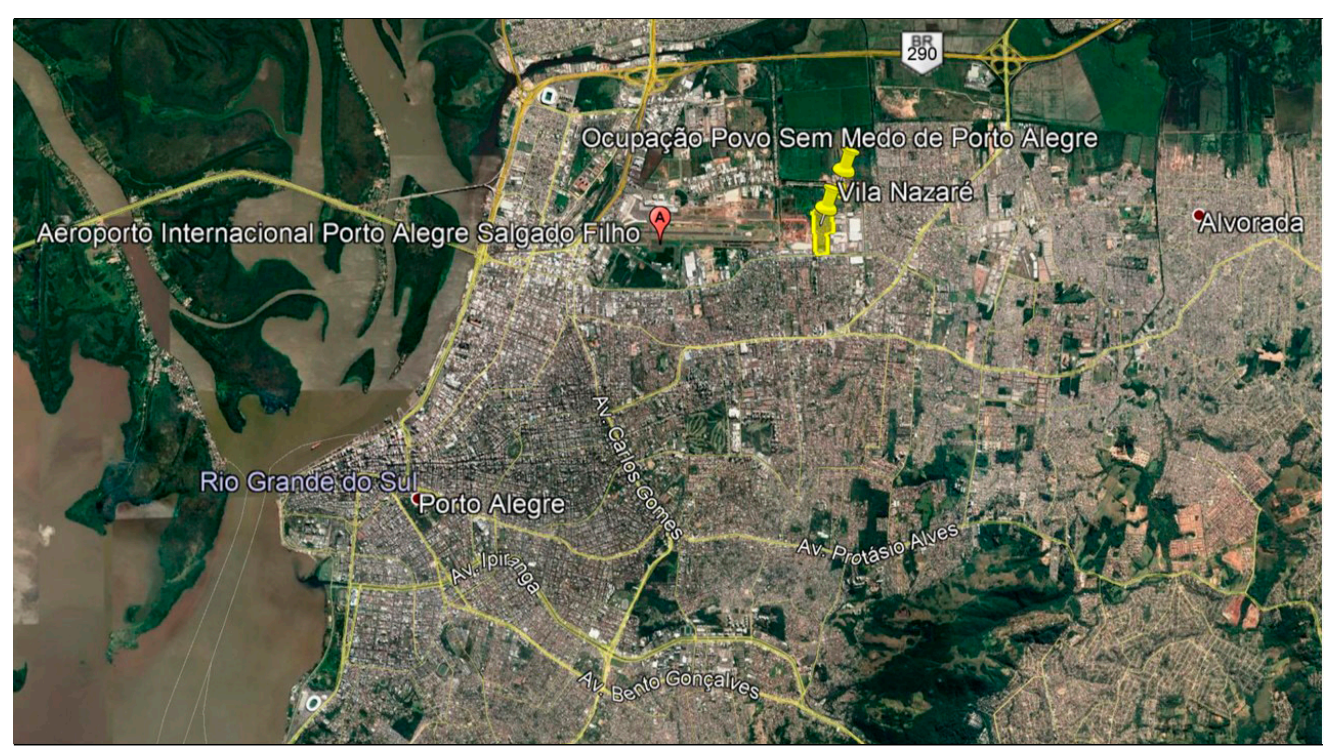

Fonte: Google-earth, 2019

Mas, para além da ATHIS, o PUE se fez também como oportunidade para o ensaio de uma nova pedagogia para o ensino de Arquitetura e Urbanismo, proposta que, na visão dos coordenadores do projeto, deve emergir desde o Sul global, vinculada aos seus temas e problemas, como alternativa de superação do ensino ancorado à tradição europeia colonizadora. Neste sentido, a proposta pedagógica do projeto é de uma educação crítica, participativa e solidária (Betto, 2018), que mobiliza o conhecimento em busca da justiça social na cidade.

\section{O território em disputa}

O acesso à moradia digna está garantido pela Constituição Federal brasileira de 1988, segundo o seu artigo 6०: "São direitos sociais a educação, a saúde, a alimentação, o trabalho, a moradia [grifo nosso], o transporte, o lazer, a segurança, a previdência social, a proteção à maternidade e à infância, a assistência aos desamparados, na forma desta Constituição" (Brasil, 1988). Portanto, não se trata de benefício outorgado por ato de caridade, mas é reconhecido como direito social.

É importante destacar este aspecto, inicialmente, já que o projeto de extensão se vinculou a comunidades e a movimentos populares que reivindicam o exercício deste direito em um território em disputa. E o lugar onde o reclamam é complexo. Muitas questões estão em pauta quando se trata da disputa Fraport/Vila Nazaré por território na Várzea do Rio Gravataí, localizada na zona norte de Porto Alegre (Figura 2). Portanto, à guisa de apresentação, é necessário delinear aspectos do lugar e do conflito fundiário posto. 
Figura 2: Mapa aproximado que destaca a Vila Nazaré, a ocupação Povo Sem Medo de Porto Alegre e a esquerda, a cabeceira da pista de pouso e decolagem do aeroporto internacional Salgado Filho.

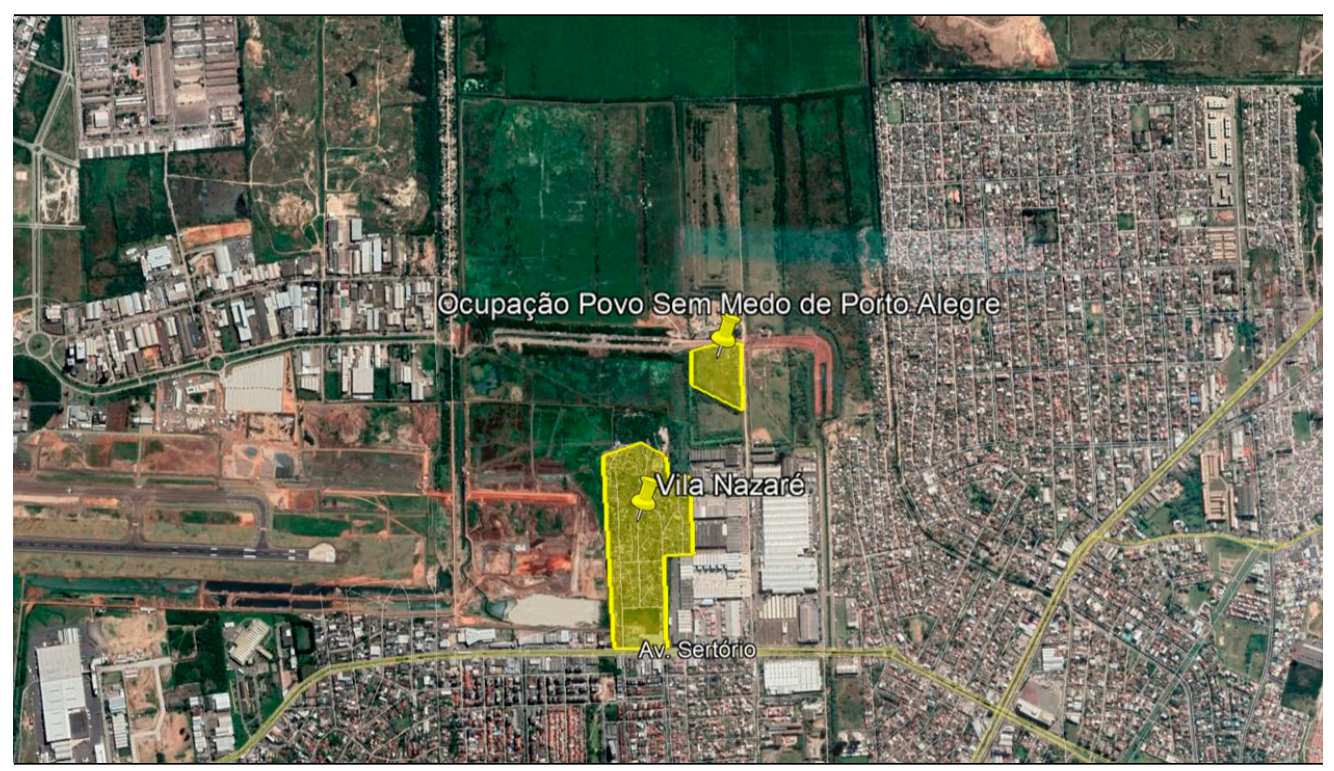

Fonte: Google-earth, 2019.

O Rio Gravataí é um curso d'água que banha diversos municípios da Região Metropolitana de Porto Alegre antes de desaguar no Delta do Jacuí. O rio corre em sua "calha" durante boa parte do ano. Mas, periodicamente, o rio extravasa para a planície alagável à sua volta, que corresponde à área denominada Várzea do Gravataí. Esse banhado existente nas suas bordas regula a vazão do rio ao funcionar como uma "esponja" - que absorve parte da água da chuva e depois a libera lentamente ao rio.

Compreende-se, desse modo, que a Várzea do Gravataí é área que "pertence" ao rio. Seu transbordamento para a planície de inundação circunvizinha não é sinônimo de tragédia. Este é um fenômeno natural que acontece periodicamente ano após ano. As catástrofes podem ocorrer quando, inadvertidamente, estas áreas são urbanizadas, regular ou irregularmente, por meio de assentamentos autoconstruídos ou por empreendimentos promovidos pelo mercado imobiliário. Esta ação social (a construção de cidade, a urbanização) é controlável pela regulação e gestão da ocupação do solo urbano, que pode evitar eventos catastróficos (alagamento, deslizamentos de terra, contaminação do solo) originados pela ocupação de áreas de risco.

Regiões ambientalmente frágeis como estas - de banhado ou de encosta, por exemplo são inadequadas à urbanização. Ocupá-las significa oferecer riscos ao meio ambiente (contaminação do solo e das águas, impacto sobre a fauna e flora, entre outros) e à sociedade (alagamento de ruas, casas, empresas e indústrias, entre outros). Por que, apesar dos riscos anteriormente delineados, parte da Várzea do Gravataí é atualmente objeto de disputa? Podemos citar alguns motivos:

1. Porque é o último grande "estoque" de terra disponível em uma das mais valorizadas áreas de Porto Alegre; 
2. Porque a área está recebendo vultosos investimentos em infraestrutura, o que, por si só, eleva sobremaneira o preço da terra;

3. Porque é uma das áreas mais acessíveis e conectadas da Região Metropolitana, por conta de sua proximidade com o aeroporto, com importantes eixos viários da cidade (como a Avenida Sertório, por exemplo), do Estado (BR 290/Freeway) e do país (BR 116); 4. Porque a ampliação da pista do aeroporto visa, sobretudo, aumentar sua capacidade operacional como terminal de transporte de cargas;

5. Porque a legislação urbanística, conforme estabelece o Plano Diretor de Desenvolvimento Urbano Ambiental de Porto Alegre/PDDUA (Porto Alegre, 2010), define como sua "vocação" o predomínio do setor produtivo (indústrias, estoques, logística), restringido ali a atividade residencial.

Em síntese, a ocupação desta área, do ponto de vista do capital e dos interesses especulativos, é cada vez mais cobiçada.

Esta região, que noutros tempos pouco interessava às empresas e ao mercado imobiliário, é hoje economicamente atraente, especialmente por conta da expectativa de ampliação da pista do aeroporto, mas também devido à extensão da Avenida Severo Dulius e à duplicação da ponte do Guaíba, sem contar que tais iniciativas encontram amparo legal no Plano Diretor de Desenvolvimento Urbano e Ambiental da cidade. Entretanto, tais obras, normas e interesses desprezam os possíveis impactos ambientais e sociais que estas transformações podem oferecer. Já é possível verificar os danos causados pelos processos de expansão urbana que vêm ocorrendo sobre as áreas de várzea e as áreas adjacentes ao aeroporto.

Porém, a região entre a cabeceira da pista do aeroporto, a Freeway e a Avenida Sertório, de fato, não está completamente "vazia": há ali, "no meio do caminho", a Vila Nazaré. Embora seus moradores não tenham o título de propriedade de seus lotes, as famílias ali residentes ocupam o local há 60 anos.

No Brasil, historicamente, é sabido que os pobres ocupam áreas alagáveis e encostas (dentre outras áreas de risco) por impossibilidade de morar em outros lugares. Ao contrário dos ricos, que dominam os espaços urbanos, pois podem comprá-los, os pobres não têm essa "liberdade de escolher" o lugar onde querem residir. Mas, eventualmente, pobres e ricos disputam a mesma localização na cidade. No caso em discussão, esses dois polos, por razões muito distintas, querem o mesmo território.

De um lado, estão a Fraport, as indústrias e empresas de logística aeroportuária (os "condomínios empresariais"), as quais enxergam naquele pedaço de terra uma oportunidade para incrementar seus negócios.

O Aeroporto de Porto Alegre ocupa uma área de 85 hectares. Para se ter uma ideia, isso representa apenas $0,0002 \%$ da superfície total do município (49.000 hectares). No entanto, em 2018 (isto é, em plena crise econômica), por esta pequena área circularam cerca de 8 milhões de passageiros, 80 mil aeronaves e 37 mil toneladas de carga. Com a concessão do aeroporto à Fraport, e considerando as previsões de ampliação da pista, este movimento deverá aumentar significativamente. Pode-se imaginar facilmente o que isso representa à valorização econômica das áreas situadas nas proximidades do aeroporto, demandadas, especialmente, por empresas de logística. 
Do outro lado da disputa estão as 1500 famílias da Vila Nazaré, que habitam a região há décadas e que, neste longo tempo, construíram estreitos laços identitários com o local e de solidariedade entre si. Parte dessas famílias quer permanecer no local. Mas são pressionadas a abandoná-lo pela retirada paulatina dos serviços públicos e da infraestrutura urbana por parte da Prefeitura Municipal. As pessoas que lá vivem enxergam naquele pedaço de terra, sobretudo, um "valor de uso": morar, cuidar de suas famílias, viver, ou, como resumem alguns moradores da Vila, ter ali "uma vida modesta, mas feliz".

É muito importante salientar que os líderes comunitários da Nazaré, nas oportunidades que tivemos de dialogar com eles, jamais se opuseram às obras do aeroporto. Entre esses líderes, sempre houve um manifesto desejo de diálogo com o poder público para busca de uma solução pactuada. Queriam que fosse estudada a possibilidade de continuar residindo nas proximidades, isto é, na região da cidade com a qual têm profundos vínculos - emprego, escolas para suas crianças, serviços de saúde, relações de cooperação e solidariedade. Tudo o que pediam é que se encontrasse uma solução dialogada, e não imposta. Contudo, todo o esforço das lideranças comunitárias foi frustrado.

A questão ambiental e os riscos à urbanização, que deveriam limitar ou permitir o acesso à terra, passam ao largo. O que esteve em pauta durante todo o ano de 2019, período em que o projeto de extensão se relacionou com os moradores da Vila Nazaré e da Ocupação Povo Sem Medo, foi: quem deve permanecer no local? Quem tem direito a ele? A Fraport, que comprou os direitos de explorar o terminal aeroportuário? Os condomínios empresariais, que realizam aterros e avançam sobre o banhado? Ou as famílias da Vila Nazaré, que desejam usufruir o direito à moradia digna, a serviços de infraestrutura, a equipamentos de uso público e comunitário, como creche, escola e praças? Quem tem, enfim, direito à cidade?

\section{Assessoria Técnica em Arquitetura e Urbanismo}

A origem da Assessoria (ou Assistência) Técnica em Arquitetura e Urbanismo está na proposição do Programa de Assistência Técnica Gratuita ao Projeto e Construção de Moradias Isoladas para Pessoas de Baixa Renda, elaborada a partir de 1976 no Sindicato de Arquitetos no Estado do Rio Grande do Sul (SAERGS), segundo Mello (2014). Após décadas de debate e construção, em 2008 foi sancionada a Lei 11.888/08 para assegurar às famílias de baixa renda assistência técnica pública e gratuita para o projeto e a construção de habitação de interesse social (Brasil, 2008).

$\mathrm{A} 2^{\mathrm{a}}$ edição do PUE pôs em discussão os alcances desta lei, exercitando-a na prática. Segundo o artigo $4^{\circ}$ da lei anteriormente citada, os serviços de assistência técnica devem ser prestados por profissionais das áreas de Arquitetura, Urbanismo e Engenharia que atuem, dentre outros âmbitos, por meio de programas de extensão ou por escritórios-modelos (EMAUs). E é neste campo que o projeto de extensão se enquadra.

A noção de programa é importante, já que pressupõe um conjunto articulado de ações continuadas, remetendo assim à necessidade de perenidade temporal das atividades. E esse, nos parece, é um aspecto importante na atividade extensionista: dar-Ihe dimensão temporal alargada, uma construção de vínculos de confiança que se solidifiquem com o tempo.

Outro aspecto debatido durante o desenvolvimento do projeto recupera polêmica que vem ocorrendo, mais recentemente, acerca da distinção entre os termos assistência ou as- 
sessoria técnica. Kapp (2018), por exemplo, contrapõe as noções de assistência e assessoria. Em resumo, a assistência remeteria à ideia de filantropia, mais associada ao Estado, de inferioridade do assistido em relação a quem o assiste; a assessoria, por sua vez, remeteria a uma perspectiva crítica dessas relações, professando maior autonomia aos protagonistas destas ações (autogestão). A razão dessa distinção é mais histórica do que teórica/etimológica, conforme a autora.

Mas é importante referir, a Lei 11.888/08 (Brasil, 2008) não trata de qualquer tipo de assistência (ou assessoria). É uma assistência "técnica". Talvez haja, no uso deste adjetivo, a intenção de afirmar a legitimidade da técnica e da ciência, em contraponto à política. A técnica/ciência seria objetiva, racional, neutra; se opondo, assim, à política, tendenciosa, posicionada. Em última análise, a assistência (ou assessoria) técnica seria atividade racional e não contaminada por desejos e ideologias. Será isso possível?

Pensamos, a partir de nossa ação extensionista, que não. Pensamos também que um dos desafios que a Universidade deve superar quando atua para além de seus muros e dialoga com a população das vilas populares e favelas, é "desconstruir essa 'hierarquia de saberes' e admitir o protagonismo popular, sem desconhecer que a universidade é (e deve ser) uma das vozes presentes na polifonia urbana" (Mello et al., 2019). Sendo assim, a Universidade deveria posicionar-se tomando por premissa três papéis: o de defensor, mediador e/ou consultor, ou seja, um trabalho técnico, mas também reconhecidamente engajado.

Para aprofundar a compreensão sobre o assunto, durante as atividades do PUE foi realizada uma roda de conversa sobre o tema ATHIS na Faculdade de Arquitetura da UFRGS. A arquiteta e urbanista Karla Moroso ${ }^{1}$ foi a convidada para dialogar com os integrantes do projeto sobre essa questão, pouco tratada nas aulas de graduação e pós-graduação. Durante essa atividade, foram discutidos aspectos da assistência técnica, como o surgimento da demanda para o trabalho em ATHIS, a relação com os movimentos sociais, as relações de confiança necessárias ao sucesso dos projetos e das construções, entre outros temas. Nesse debate, a manifestação mais contundente partiu de uma estudante de graduação. Ela colocou uma grande dúvida quanto à formação e ao futuro profissional que lhe espera. Referiu, na ocasião, que tem participado de outro projeto de extensão em que é a única estudante de Arquitetura e Urbanismo. E que ali é solicitada para que opine sobre soluções de infraestrutura urbana, sistemas estruturais, desenho urbano. Para seu desassossego, boa parte das vezes ela não tem respostas, pois as disciplinas da graduação não lhe apresentaram os conhecimentos necessários para resolver questões que considera corriqueiras. Esse desconhecimento era, também, a causa de sua insegurança em relação à atuação profissional. Que desafios a aguardavam após a diplomação?

O relato desta estudante evidencia, em parte, o fracasso da formação a ela oferecida. Como pôr à disposição dos estudantes as ferramentas necessárias ao exercício profissional? Que parte da formação é efetivamente útil aos egressos em seu enfrentamento com o cotidiano laboral? Não temos a pretensão de responder a estas perguntas. Entretanto, pa-

1) Karla Moroso tem extensa experiência em assistência técnica. Seu escritório - AH! Arquitetura Humana - foi vencedor do $13^{\circ}$ Prêmio Arquiteto e Urbanista do Ano, na categoria Setor Público, por seu trabalho de assistência técnica e de elaboração de material sobre o tema para o Conselho de Arquitetura e Urbanismo de Santa Catarina. O prêmio é outorgado pela Federação Nacional de Arquitetos e Urbanistas (FNA). 
receu-nos que exercitar e discutir a ATHIS, durante o projeto de extensão, era uma maneira de problematizar estas lacunas formativas e de evidenciar uma relevante possibilidade de trajetória profissional.

\section{Atividades: Vila Nazaré e Ocupação Povo Sem Medo de Porto Alegre}

Em 2019, o PUE realizou ações e acompanhou atividades nos dois territórios já referidos, a Vila Nazaré e a Ocupação Povo Sem Medo de Porto Alegre. Delinearemos a seguir os trabaIhos realizados em ambos os espaços.

Iniciaremos relatando as atividades desenvolvidas na Vila Nazaré. Ali, o projeto de extensão acompanhou o processo de remoção das famílias pelo Departamento Municipal de Habitação (DEMHAB) da prefeitura municipal de Porto Alegre. Foram poucas e pontuais as ações realizadas na Vila Nazaré ao longo do ano. Durante a maior parte do tempo, a comunidade acadêmica foi observadora participante de processos como, por exemplo, as mobilizações, manifestações e passeatas que reivindicavam o diálogo com o poder público municipal - caminhadas por avenidas importantes da cidade, vigílias em frente à sede da Justiça Federal, diálogo entre lideranças comunitárias e a população da vila popular.

Além disso, o projeto de extensão reuniu notícias publicadas acerca da disputa Fraport/ Vila Nazaré. A intenção, neste caso, foi acompanhar a narrativa construída pelos órgãos de imprensa local.

Foi possível perceber, preliminarmente, que há empresas de comunicação mais ou menos engajadas na remoção das famílias da vila e na viabilização do negócio da empresa multinacional operadora de aeroportos. Ao contrário do que se poderia esperar de um jornalismo plural, onde as posições em disputa apresentam seus argumentos, parece-nos evidente que alguns periódicos têm funcionado como defensores da causa da Fraport, advogando em seu favor e oferecendo pouco espaço para o contraponto. A narrativa da imprensa nos parece querer garantir o exercício do "direito de ganhar dinheiro" - e isso em detrimento do direito à moradia, consagrado pela nossa Constituição.

Outra atividade importante ocorrida por solicitação do MTST e da Associação de Moradores da Vila Nazaré (AMOVIN) foi a participação de representante do projeto de extensão na reunião da Comissão de Urbanização, Transporte e Habitação (CUTHAB) da Câmara de Vereadores de Porto Alegre, que aconteceu em agosto de 2019. Participaram dessa reunião representantes do Departamento Municipal de Habitação (DEMHAB), da Associação de Moradores da Vila Nazaré (AMOVIN), do MTST, da Associação Amigos da Terra Brasil, do Instituto de Arquitetos do Brasil - Departamento Rio Grande do Sul (IAB/RS), além de vereadores.

Nessa reunião, debateram-se o processo de realocação das famílias e as denúncias de violação de direitos humanos no que tange à moradia digna. O representante do PUE, neste momento, se manifestou na qualidade de técnico, mas também de defensor das demandas da associação de moradores e do MTST ao expor o conflito fundiário posto. Solicitou, finalmente, que a Fraport e o poder público dialogassem com a comunidade da Vila Nazaré para que, juntos, buscassem uma alternativa que contemplasse as justas demandas das famílias ali residentes.

Outra atividade importante ocorrida durante esta edição do projeto de extensão foi a visita de um grupo de participantes do Seminário “Cidade, Habitação, Lutas Urbanas”, em setembro 
de 2019, à Vila Nazaré. Nessa visita - realizada durante uma tarde -, estudantes de graduação e pós-graduação, além de professores da Faculdade de Arquitetura da UFRGS e da Faculdade de Arquitetura e Urbanismo da Universidade de São Paulo (USP) puderam percorrer as ruas, os becos e as vielas da Vila e verificar o resultado das demolições e da remoção forçada.

Estudantes e professores ouviram dos moradores que o poder público municipal não oferecia às famílias da Vila Nazaré nem mesmo "o direito de terem direito", uma vez que, para acelerar a desocupação da área, estavam sendo retirados os poucos serviços públicos e comunitários disponíveis. Puderam, também, ouvir relatos sobre como a violenta ação de remoção causa profundo impacto material e emocional na vida da comunidade e das famílias.

Finalmente, uma última ação foi iniciada: o mapeamento do processo de derrubada (arrasamento) das residências da Vila Nazaré, empreendidas pelo Departamento Municipal de Habitação (DEMHAB).

Essas foram as ações realizadas na Vila Nazaré no transcorrer de 2019. Passemos a relatar agora as atividades efetuadas na Ocupação Povo Sem Medo de Porto Alegre.

A primeira atividade, que aconteceu na Povo Sem Medo de Porto Alegre - ao que denominamos "vivência" -, foi uma visita de reconhecimento ao local, em maio de 2019. Nessa ocasião, os estudantes fizeram uma caminhada pelo território da Ocupação e participaram de roda de conversa com os moradores, discutindo temas como direito à moradia e à cidade, acesso à terra urbanizada, pobreza urbana, problemas habitacionais e técnicos da urbanização de vilas populares e favelas. Dias depois, foi realizada uma atividade na Universidade, ao que denominamos "oficina", onde integrantes do MTST e moradores da Ocupação vieram à Faculdade de Arquitetura discutir as impressões sobre a vivência e elaborar propostas de interação.

Foram levantadas muitas propostas, organizadas em dois eixos: a) intervenções de alcance individual e; b) de alcance coletivo. À proposta do eixo individual, demos o nome de Assistência Técnica para Habitação - Arquiteto de Família. Nela, cada grupo de 3 estudantes atenderia a um número definido de casas. Seriam feitos levantamento, desenho técnico, reconhecimento de problemas na edificação (estabilidade, orientação, etc.). Após esse "reconhecimento", os estudantes, sob supervisão dos professores, elaborariam sugestões e orientações para melhorar a condição das habitações. Essa proposta não foi adiante, em virtude de outras demandas consideradas mais urgentes, como a do eixo de alcance coletivo.

O eixo de alcance coletivo elegeu a proposta de realização de mutirão de reconstrução do galpão comunitário e de construção de banheiros ecológicos durante os fins de semana. Foram elaborados os desenhos técnicos de reconstrução do galpão, quantificados os materiais, elaborada a maquete para apresentação e discussão da proposta com os moradores da Ocupação. Este trabalho terá continuidade, com conclusão prevista para o primeiro semestre de 2020.

Além das atividades anteriormente descritas, o projeto de extensão discutiu também a necessidade de dar visibilidade, em caráter de denúncia, à luta por moradia digna das famílias da região. Como consequência, o projeto de extensão realizou dois produtos: um programa audiovisual em parceria com a TV-UFRGS e uma série de cartões-postais.

O programa, produzido pela TV UFRGS, foi veiculado no quadro "Conhecendo a UFRGS" e está atualmente disponível em seu canal do YouTube (UFRGS TV, 2019). O filme transita entre a Universidade e a Ocupação, captando depoimento de professores, estudantes, 
bolsistas, moradores da Ocupação e integrantes do movimento social. O programa revela a condição de moradia das famílias pobres e o esforço do movimento social na reivindicação do cumprimento do direito de moradia digna.

Os cartões-postais, por sua vez, foram impressos com ajuda do fomento à extensão da Pró-Reitoria de Extensão da Universidade (PROREXT/UFRGS). Foram confeccionados 20 tipos de cartões-postais a partir das fotografias dos integrantes do projeto de extensão. Essas imagens foram selecionadas coletivamente e representam o olhar do grupo sobre o que é a Povo Sem Medo. No verso do material está gravado o artigo da Constituição Federal Brasileira de 1988 que refere que a moradia é parte dos direitos sociais. A tiragem dos cartões-postais foi de 5.000 exemplares, os quais foram distribuídos pelos integrantes do projeto em oportunidades como aulas, seminários, fóruns públicos, visitas à Vila Nazaré e à Ocupação, entre outros espaços.

\section{A extensão e uma outra universidade possível}

A cada vivência, a coordenação do PUE incentivou que os participantes (alunos e professores) realizassem relatos em formato de descrições, poemas, croquis, enfim, depoimentos com as impressões sobre a Ocupação PSM/POA ou sobre a Vila Nazaré. Encontramos neste hábito um modo de sistematizar os registros, a partir de diferentes percepções e abordagens, sobre o processo e a relação universidade/sociedade que vai sendo construída durante o desenrolar do projeto. Entre os relatos recebidos, destacamos o que segue:

"Depois de 7 anos e meio de faculdade, ontem foi a primeira vez que bati um nível... gostei". Depoimento de um egresso do curso de Arquitetura e Urbanismo da UFRGS, integrante do projeto de extensão PUEs (2019)

Este breve depoimento foi enviado por um dos integrantes do projeto de extensão por meio de um aplicativo de mensagens. $O$ autor, arquiteto e urbanista diplomado há cerca de um ano, faz revelação que chama a atenção para aspectos relacionados ao papel da universidade. Essa fala, para nosso espanto, nos leva a refletir sobre a extensão como uma atividade provocadora de outra formação possível a partir de duas perguntas suscitadas pelo relato do egresso: i) qual é a formação que as nossas escolas de Arquitetura e Urbanismo têm oferecido? ii) que utilidade tem a formação oferecida por nossas escolas?

É necessário reconhecer que nossos modelos de ensino de Arquitetura e Urbanismo baseiam-se nos modelos ateliê-mestre-aluno da École de Beaux Arts parisiense do século XIX. No caso dos cursos de Arquitetura, inclui-se ainda a centralidade da composição arquitetônica, espinha dorsal dos respectivos planos pedagógicos. Neste sentido, a formação em Arquitetura e Urbanismo dialoga e toma como referência o exercício profissional baseado nos paradigmas dos países do Norte global. Estamos de costas para os países do Sul, nossos temas, problemas, modos de fazer e pensar. A extensão, particularidade latino-americana, pode e deve estimular a reflexão sobre novos modelos de ensino e pesquisa.

Essas preocupações recuperam, em alguma medida, as pautas e reivindicações da Reforma de Córdoba, ocorrida em 1918 (Neto, 2011). Não apenas na perspectiva crítica ao autoritarismo universitário e à reprodução da tradição europeia. A experiência da Reforma de Córdoba sinaliza para a necessidade de democratização do conhecimento. Colocar a 
extensão no centro do fazer universitário significa, parece-nos, dar relevância à sua missão social, transbordando-a para além de seus limites.

É por essa razão que o PUE se faz também como ensaio de uma nova pedagogia para o ensino de Arquitetura e Urbanismo, pois o faz a partir da extensão universitária. Deixa de ser, portanto, atividade desprestigiada e passa a ser a articuladora do tripé universitário. Tomando como referência a centenária experiência de Córdoba, é proposta que emerge desde o Sul global, vinculada aos seus temas e problemas, como alternativa de superação de práticas pedagógicas já experimentadas. A extensão universitária seria, por isso, um dos fatores de desalienação da universidade (Betto, 2018).

Neste sentido, a proposta do projeto Práticas Urbanas Emergentes é de uma educação crítica, participativa e solidária (Betto, 2018), a qual movimenta o conhecimento em busca da justiça social na cidade. Sendo assim, não se propõe apenas a contemplar a realidade, distante. Quer interagir, se envolver, construir vínculos, para que a sociedade, da qual faz parte, supere suas injustiças.

E, neste movimento de relação e compromisso, o projeto de extensão colocou em primeiro plano dois conceitos fundamentais do pensamento do educador Paulo Freire: a dialogicidade e a práxis (Freire, 1987). As concepções de dialogicidade e práxis pressupõe uma relação de igualdade, de horizontalidade onde o educador "não se sente dono do tempo, nem dono dos homens, nem libertador dos oprimidos. Com eles se compromete, dentro do tempo, para com eles lutar" (p. 27). Neste sentido, o mundo deve ser forjado com ele e não para ele, em comunhão. Foi o que propôs fazer o projeto de extensão Práticas Urbanas Emergentes.

\section{Considerações finais}

Até a conclusão deste texto, a remoção das famílias da Vila Nazaré para o Loteamento Senhor do Bom Fim e para o Condomínio Irmãos Maristas ainda não havia sido finalizada. Esse processo vem desmanchando um tecido social e uma relação de vizinhança construídos ao longo de décadas. A Ocupação Povo Sem Medo, por sua vez, tem crescido vertiginosamente em população e número de barracos. Vivem-se movimentos paralelos e opostos: a Vila Nazaré está sendo destruída, e a Ocupação está se transformando em uma Vila. É algo que nos instiga não somente a dar continuidade ao projeto de extensão universitária, mas também coloca importantes questões para a pesquisa e o ensino.

Neste segundo ano de atividades do PUE, ficou perceptível para os integrantes do projeto que o fazer extensionista é, em si, uma prática ético-política. O exercício de compreender melhor as arenas e os atores na disputa pelo território foi uma constante nesta atividade.

Nosso desejo é que as iniciativas oferecidas por meio do PUE venham a fortalecer a compreensão do papel essencial da Universidade na formação profissional (mas como sugerido, por meio de uma outra universidade possível) e da responsabilidade que todos nós temos quando assumimos realizar extensão universitária, por meio do diálogo entre saberes sobre a cidade.

O PUE teve o mérito também de colocar em pauta, no âmbito da graduação, questões como a pobreza urbana, a cidade autoconstruída, a necessidade de projetos arquitetônicos e urbanísticos de caráter social, algo pouco recorrente na vida acadêmica. A perspectiva 
crítica, participativa e solidária do projeto de extensão distanciou-o de uma atitude altruísta, mas descompromissada.

Neste sentido, os conceitos paulofreireanos de dialogicidade e práxis foram capitais. Eles se contrapuseram à ação implementada pelo poder público local no que se refere a transferência das famílias da Vila Nazaré. Se a ação da prefeitura era autoritária e desprezava o diálogo com a população e o movimento social, nosso esforço foi no sentido de desmanchar o autoritarismo do saber técnico-científico e demonstrar, na prática, aos estudantes, que é possível realizar uma ação que acolha os interesses, formas de fazer e sonhos populares. E só a extensão universitária tem condições de realizar isso de uma maneira radical.

\section{Referências bibliográficas}

Andrade, C. D. (2002). Poesia completa: conforme as disposições do autor. José Aguilar.

Betto, F. (2018). Por uma educação crítica e participativa. Anfiteatro.

Brasil (1988). Constituição da República Federativa do Brasil. Centro Gráfico.

(2008). Lei 11.888, de 24 de dezembro de 2008, Assegura às famílias de baixa renda assistência técnica pública e gratuita para o projeto e a construção de habitação de interesse social e altera a Lei 11.124, de 16 de junho de 2005. http://www.planalto.gov.br/ccivil_03/_Ato2007-2010/2008/Lei/L11888.htm

Freire, P. (1987). Pedagogia do oprimido. Paz e Terra.

Kapp, Silke (2018). Grupos sócio-espaciais ou a quem serve a assessoria técnica. Revista Brasileira de Estudos Urbanos e Regionais, 20(2), 221-236. São Paulo. https://doi.org/10.22296/2317-1529.2018v20n2p221

Mello, B. C. E. (2014). Sindicato de Arquitetos no Estado do Rio Grande do Sul: memórias de quatro décadas (1973-2013). Livraria do Arquiteto.

Mello, B. C. E.; Nodari, G. R.; Lersch, I. M.; Rovati, J. F. (2019). Defensor, mediador, consultor: posicionando a universidade. En: Ferreira, L.; Oliveira, P.; lacovini, V. (eds.). Dimensões do intervir em favelas: desafios e perspectivas (pp. 233-240). Peabiru TCA / Coletivo LabLaje.

Neto, J. A. F. (2011). A reforma universitária de Córdoba (1918): um manifesto por uma universidade latina-americana. Revista Ensino Superior Unicamp, 62-70. Campinas. http://www.gr.unicamp.br/ceav/revistaensinosuperior/ed03_junho2011/pdf/10.pdf

Porto Alegre (2010). Plano Diretor de Desenvolvimento Urbano e Ambiental. Porto Alegre. http://lproweb.procempa.com.br/pmpa/prefpoa/spm/usu_doc/planodiretortexto.pdf

UFRGS TV (21 de junho de 2019). Práticas urbanas emergentes - Conhecendo a UFRGS. Arquivo de vídeo. https://www.youtube.com/watch?v=k-k32wGm8QU 